\title{
Article \\ Connexin46 Expression Enhances Cancer Stem Cell and Epithelial-to-Mesenchymal Transition Characteristics of Human Breast Cancer MCF-7 Cells
}

\author{
Rodrigo A. Acuña ${ }^{1, *,+}$ (D), Manuel Varas-Godoy ${ }^{2,+}\left(\mathbb{D}\right.$, Diego Herrera-Sepulveda ${ }^{3}$ and Mauricio A. Retamal ${ }^{4,5, * \mathbb{D}}$ \\ 1 Centro de Medicina Regenerativa, Facultad de Medicina, Clínica Alemana Universidad del Desarrollo, \\ Santiago 7780272, Chile \\ 2 Centro de Biología Celular y Biomedicina (CEBICEM), Facultad de Medicina y Ciencia, \\ Universidad San Sebastian, Santiago 7510157, Chile; manuel.varas@uss.cl \\ 3 Carrera de Medicina Universidad del Desarrollo, Facultad de Medicina, \\ Clínica Alemana Universidad del Desarrollo, Santiago 7780272, Chile; dherreras@udd.cl \\ 4 Centro de Fisiología Celular e Integrativa, Facultad de Medicina Clínica Alemana, \\ Universidad del Desarrollo, Santiago 7780272, Chile \\ 5 Programa de Comunicación Celular en Cáncer, Facultad de Medicina Clínica Alemana, \\ Universidad del Desarrollo, Santiago 7780272, Chile \\ * Correspondence: rodrigoacuna@udd.cl (R.A.A.); mretamal@udd.cl (M.A.R.) \\ + R.A.A. and M.V.-G. contributed equally to this work.
}

\section{check for} updates

Citation: Acuña, R.A.; Varas-Godoy, M.; Herrera-Sepulveda, D.; Retamal, M.A. Connexin46 Expression Enhances Cancer Stem Cell and Epithelial-to-Mesenchymal Transition Characteristics of Human Breast Cancer MCF-7 Cells. Int. J. Mol. Sci. 2021, 22, 12604. https://doi.org/ $10.3390 /$ ijms222212604

Academic Editors: Roberto Bei and Giovanni Barillari

Received: 31 August 2021

Accepted: 3 November 2021

Published: 22 November 2021

Publisher's Note: MDPI stays neutral with regard to jurisdictional claims in published maps and institutional affiliations.

Copyright: (c) 2021 by the authors. Licensee MDPI, Basel, Switzerland. This article is an open access article distributed under the terms and conditions of the Creative Commons Attribution (CC BY) license (https:/ / creativecommons.org/licenses/by/ $4.0 /)$.

\begin{abstract}
Connexins (Cxs) are a family of proteins that form two different types of ion channels: hemichannels and gap junction channels. These channels participate in cellular communication, enabling them to share information and act as a synchronized syncytium. This cellular communication has been considered a strong tumor suppressor, but it is now recognized that some type of Cxs can be pro-tumorigenic. For example, Cx46 expression is increased in human breast cancer samples and correlates with cancer stem cell (CSC) characteristics in human glioma. Thus, we explored whether Cx46 and glioma cells, can set up CSC and epithelial-to-mesenchymal transition (EMT) properties in a breast cancer cell line. To this end, we transfected MCF-7 cells with Cx46 attached to a green fluorescent protein (Cx46GFP), and we determined how its expression orchestrates both the gene-expression and functional changes associated with CSC and EMT. We observed that Cx46GFP increased Sox2, Nanog, and OCT4 mRNA levels associated with a high capacity to form monoclonal colonies and tumorspheres. Similarly, Cx46GFP increased the mRNA levels of n-cadherin, Vimentin, Snail and Zeb1 to a higher migratory and invasive capacity. Furthermore, Cx46GFP transfected in MCF-7 cells induced the release of higher amounts of VEGF, which promoted angiogenesis in HUVEC cells. We demonstrated for the first time that Cx46 modulates CSC and EMT properties in breast cancer cells and thus could be relevant in the design of future cancer therapies.
\end{abstract}

Keywords: Connexin46; breast cancer; cancer stem cells; epithelial-to-mesenchymal transition; stemness

\section{Introduction}

Connexins (Cxs) are a family of transmembrane proteins that have the unique property to form two different types of ion channels: hemichannels and gap junction channels [1]. Hemichannels are formed by six Cx subunits and, when they open, communicate the cytoplasm with the extracellular milieu [2]. When two hemichannels coming from two different cells make contact, they form a gap junction channel, and due to its dispositions at the plasma membrane, these channels allow the exchange of ions and molecules up to $\sim 1.5 \mathrm{kDa}$ between the cytoplasms of these neighboring cells [1]. Under normal conditions, almost all cell types in the human body express at least one type of $C x$ and therefore have the capability to interconnect with other cells, share information and act as a synchronized syncytium. This cellular communication has been considered as a tumor suppressor [3], 
and a decrease in Cx expression has been strongly correlated with the appearance of several types of cancer [4]. However, currently it is recognized that there are some types of Cxs that seem to be pro-tumorigenic [4]; one of these, under physiological conditions, Cx46 is almost exclusively expressed in the eye lens [5]. However, this Cx may also have an important role in cancer progression. Thus, despite the seminal studies using animal models of lung and bone cancer in which a decrease of Cx46 mRNA levels was observed [6,7], more recent studies show that $\mathrm{Cx} 46$ protein levels are increased in human samples of infiltrating breast carcinoma [8] and glioblastoma [9]. In human glioblastoma, Cx46 expression was correlated with cancer stem cell (CSC) proliferation, self-renewal, and propagation, and negatively correlated with patient survival $[9,10]$. Similarly, the use of siRNA against Cx46 inhibited the tumor growth of MCF-7 (breast adenocarcinoma cell line) [8] and Y79 (human retinoblastoma cell line) [11] cells in a mouse xenograft model. Because it is very well known that only CSCs can initiate a tumor in xenograft models [12-14], the presence of Cx46 in human cancer could be considered a factor that increases CSC phenotypes in certain types of cancer such as breast cancer. Additionally, to metastasize, cancer cells must gain migratory and invasive characteristics, and they can do that through a process known as the epithelial-to-mesenchymal transition (EMT) [15]. Cxs have been reported to participate in EMT in cancer related processes [16]. Despite this evidence, as far as we know the effect of Cx46 at the cellular and molecular levels in breast cancer cells has never been explored, nor has its relationship with the properties of CSC and EMT been established. Therefore, we explored how the expression of Cx46 in a human breast cancer cell line could enhance its CSC and EMT properties. To this end, we transfected MCF-7 cells with Cx46 attached to the green fluorescent protein MCF-7Cx46GFP, and we determined how its expression orchestrates both gene-expression and functional changes associated with CSC and EMT. We observed that Cx46GFP expression induced an increase of mRNA levels of CSC transcription factors such Sox2, Nanog, and OCT4, which were associated with a high capacity to form monoclonal colonies and tumorspheres. On the other hand, Cx46GFP increased the mRNA levels of n-cadherin, Vimentin, Snail, and Zeb1, according a higher migratory and invasive capacity. Interestingly, the supernatant of MCF-7Cx46-GFP presents higher amounts of VEGF, which was associated with an angiogenic effect when it was placed over HUVEC cells. For the first time, we showed a potent effect of Cx46 on a cell line derived from breast cancer in terms of CSC and EMT induction, and these results are congruent with previous results obtained in glioma. Thus, our work supports the hypothesis that $\mathrm{C} \times 46$ is pro-tumorigenic in diverse types of cancers and should be considered in the design of future cancer therapies.

\section{Results}

\subsection{Over-Expression of Cx46 Does Not Modify the Rate of MCF-7 Cell Division}

Recently, Cx46 has been involved in the maintenance of CSCs in glioblastoma [9]; however, the effect of $\mathrm{C} \times 46$ on breast cancer stem cell properties was unknown. To explore this possibility, we transfected Cx46GFP in MCF-7 cells, which is a cell line derived from a hormone dependent ductal adenocarcinoma [17]. Under control conditions MCF-7 cells express very low levels of $\mathrm{Cx} 46$, which, in Western blot (WB) analyses, appears to have $\sim 50 \mathrm{kDa}$ (Figure 1A). As expected, MCF-7 cells transfected with Cx46GFP (MCF-7Cx46-GFP) present a prominent band of $\sim 68 \mathrm{kDa}$, which is the sum of the molecular weights of Cx46 and GFP (Figure 1A). Also, a band of about $50 \mathrm{kDa}$ was observed in these cells, most likely corresponding to the $\mathrm{C} \times 46$ endogenously expressed and/or due to a proteolytic cleavage of GFP, which has been observed in other systems $[18,19]$. As a comparative control of aggressiveness, we used a triple negative cell line known as MDA-MB-231 [20,21]. This cell line does not express Cx46. However, the Cx43 expression was observed (Figure 1A). Because one of the major cancer cell features is their high rate of proliferation, we tested whether Cx46 can enhance this property in MCF-7 cells. Under our control conditions, the MCF-7, MCF-7Cx46-GFP, and MDA-MB-231 cell lines showed the same rate of cell division after 5 days in culture (Figure 1B). Thus, Cx46 expression was not associated with 
increased or varied changes in cell division. MCF-7Cx46-GFP observed under a fluorescent microscope showed that Cx46 was located mostly in a cytoplasmic disposition (Figure 1C), accordingly gap junction-like structures were not often observed.

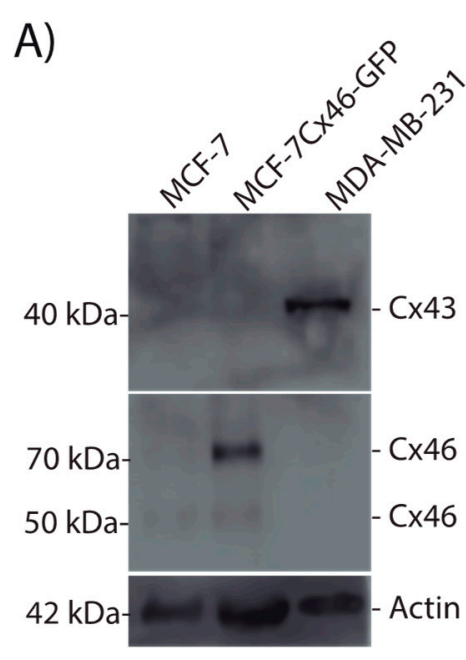

C)

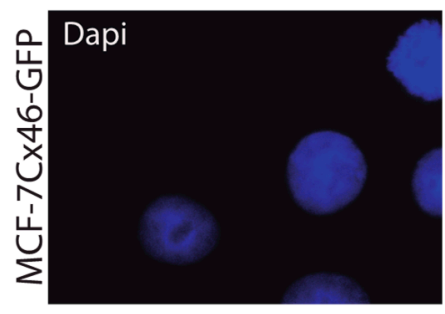

B)
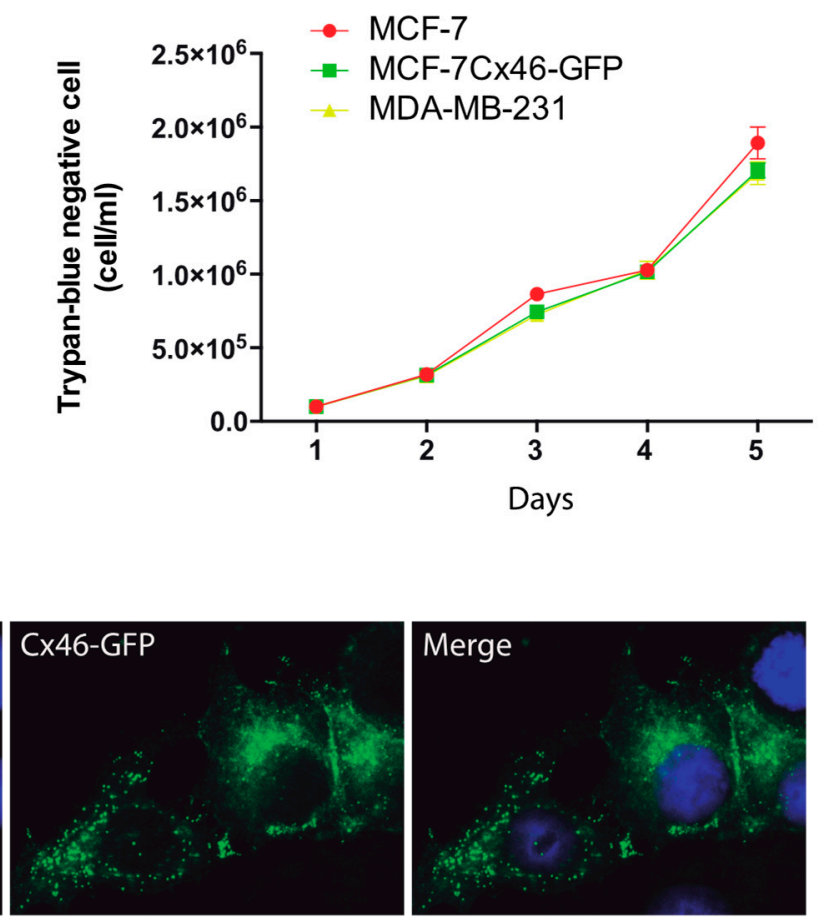

Figure 1. Connexin 46-GFP overexpressed in MCF-7 cells does not modify the rate of cell division. MCF-7 breast cancer cells were transfected with the human connexin Cx-46 gene inserted in a pcmV6-AC-GFP plasmid and selected by neomycin resistance. (A) Representative images of three independent Western blots of MCF-7, MCF-7Cx46-GFP, and MDAMB-231 cell lysates; immunoblots were incubated with anti Cx46, and anti-beta Actin (Santa Cruz Biotechnology; 1:2500). Protein bands were detected using Immobilon Forte Western horseradish protein (HRP) substrate and visualized with a LI-COR CDigit System. (B) A trypan blue dye exclusion test determined the number of viable cells. MCF-7, MCF7Cx46-GFP, and MDAMB-231 were seeded, and the trypan blue negative cells were counted in a Neubauer chamber. The cells were counted every day until the fifth day. (C) Representative fluorescence images of MCF-7Cx46-GFP cell nuclei were visualized with Dapi (left), and Cx46 was visualized with the GFP tag in the C-terminal portion of Cx46 (middle). Images were obtained using a Nikon Eclipse Ti-U inverted microscope. Data are presented as the mean of three independent experiments +/ - SEM.

\subsection{Cx46 Increases the Expression of CSC Related Genes and Funtional Characteristics}

It is well known that CSC stemness has been related to poor patient prognosis in several types of cancers [22-24] whose properties are driven by transcription factors, the most important being OCT4, Sox2, and Nanog [25]. In our breast cancer cell model, the expression of Cx46GFP increased mRNA levels of OCT4 and Sox2; however, the Nanog mRNA levels were unchanged (Figure 2A). The analysis of these results indicated that OCT4 and Sox 2 increased $3.7 \pm 0.8$ and $2.4 \pm 0.4$ times their levels, respectively, compared to non-transfected MCF-7 cells. Both OCT4 and Sox2 have been strongly correlated to the acquisition of CSC characteristics in breast cancer cells [26,27]. If Cx46 increases these CSC-associated transcription factors, it could be expected that the MCF-7 expression of this protein would show enhanced CSC functional characteristics, such as formation of 
clonogenic colonies and tumorspheres [28,29]. The clonal growth of MCF-7 was $40 \%$ lower compared to MCF-7Cx46-GFP capacity (Figure 2B,C). Additionally, MCF-7 and MCF-7Cx46GFP were cultured in ultralow attachment plates with tumorsphere supplements for two weeks, and under this condition Cx46-expressing cells formed 36\% larger tumorspheres compared to those from MCF-7 (WT) (Figure 2D,E). These results confirm that Cx46 expression is sufficient to induce a CSC-like phenotype in hormone-dependent breast cancer cells.

A)

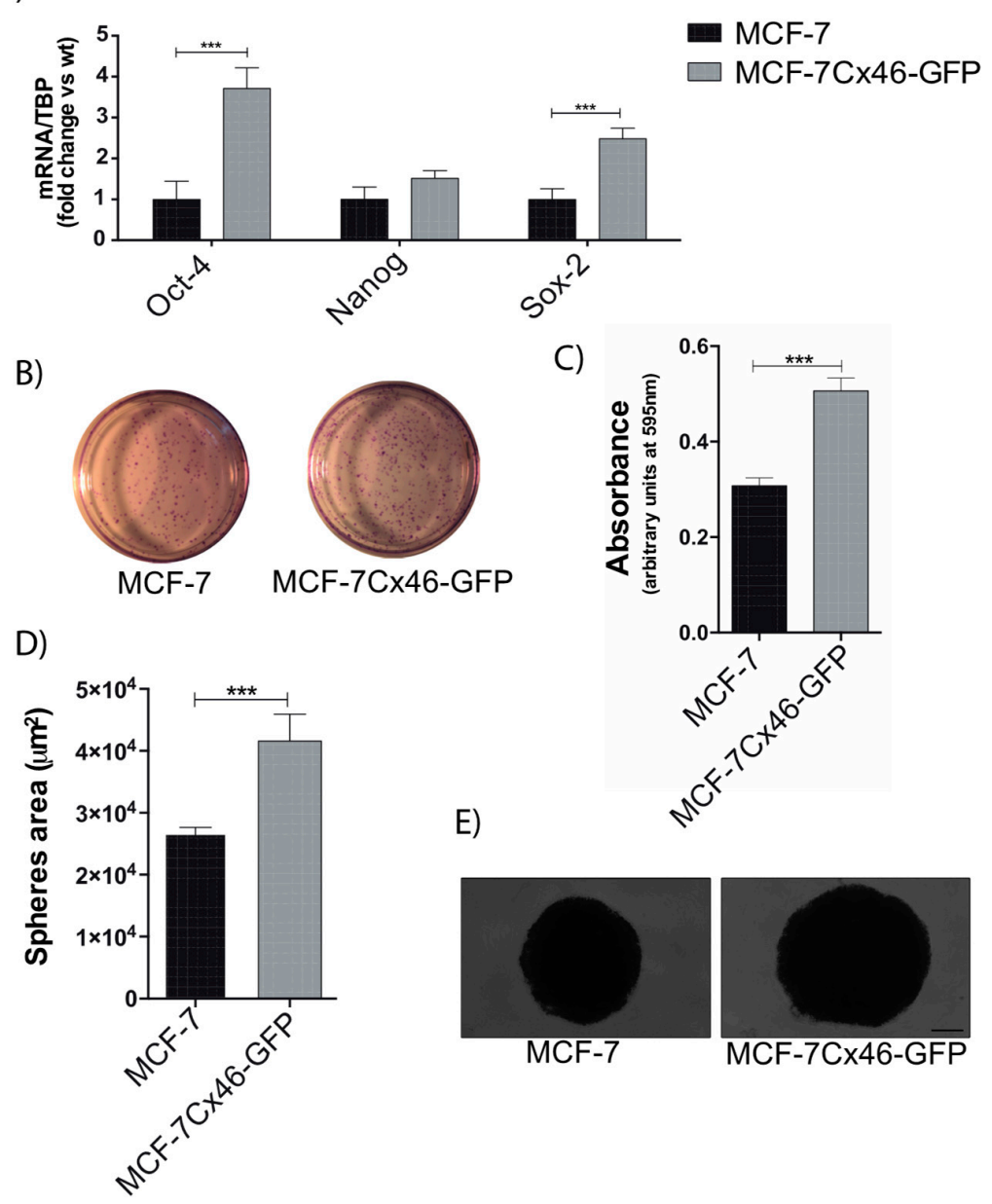

Figure 2. Cx46 increases the expression of CSC-related genes and CSC stemness. (A) Cancer stem cell-related genes were evaluated by measuring the mRNA levels of Oct4, Nanog, and Sox 2 genes by qRT-PCR in MCF-7 and MCF-7Cx46-GFP breast cancer cells; data represent the mean of three independent experiments +/ - SEM. (B) Clonogenic potential of MCF-7 and MCF-7Cx46-GFP breast cancer cells. Representative images of clonogenic assay were fixed and stained with crystal violet solution. (C) Cells were dissolved with lysis buffer and absorbance was measured at $595 \mathrm{~nm}$ (arbitrary units at $595 \mathrm{~nm}$ ). The results represent the means of three independent experiments +/ - SEM. (D) The graph represents the comparison of sphere diameters between MCF-7 and MCF-7Cx46-GFP before 3 weeks of culture. (E) Representative image of 3-week sphere morphology of MCF-7 and MCF-7Cx46-GFP cells; scale bar $100 \mu \mathrm{m}$. Data are presented as the mean of three independent experiments $+/-$ SEM. ${ }^{* * *} p<0.001$. 


\subsection{Cx46 Increases the Expression of EMT Related Genes and Functional Characteristics}

Another important aspect of cancer progression is the property of some cells to detach from the primary tumor and migrate to a local lymphovascular system, and then to distant organs in a process known as metastasis [30]. This process is so important that most of deaths associated with cancer results from it [30]. Therefore, we explored the effect of Cx46 expression on the EMT process in MCF-7 WT cells and found that the expression of Cx46GFP increased the mRNA levels of Snail (1.7 \pm 0.4 times), Zebt1 (1.9 \pm 0.2 times), $\mathrm{n}$ cadherin (3.8 \pm 1.0 times), and vimentin (15.1 \pm 3.0 times), all of which are well known EMTrelated genes (Figure $3 \mathrm{~A}$ ). The capacity to migrate and invade new tissues is characteristic of mesenchymal-like cells [31,32]. We then compared the MCF-7 WT, MCF-7Cx46-GFP, and MDA-MB-231 cell capacity to migrate and invade in vitro. To explore migration, we performed a scratch assay [33]. We studied the migratory capacity of these three breast cancer cell lines up to $16 \mathrm{hrs}$. After this time, it was evident that MCF-7Cx46-GFP migrated faster than MCF-7 WT cells (Figure 3B). Interestingly, the rate of migration of MCF-7Cx46GFP was not different compared to highly migrative MDA-MB-231 (Figure 3C). However, metastatic cells not only need to move faster but also need to release metalloproteinases to pass between the tissues and thus be able to reach the lymphatic and/or blood tissue. To study cancer cell invasive capacity, cells were placed in an extracellular-like matrix and were induced to actively pass through it following attractants [34]. Our results show that $22 \pm 2$ of MCF-7 WT cells were able to cross the Matrigel after $24 \mathrm{~h}$ (Figure 3D,E). In the same time frame, $58 \pm 6$ MCF-7Cx46-GFP and $115 \pm 10$ MDA-MB-231 cells could also cross (Figure 3D,E). Because is known that transfection per se, can affect some cell properties, we performed transfection control using plasmids coding for GFP alone (MCF-7 GFP). Additionally, if our results were indeed because of Cx46, we transfected MCF-7 with Cx46 without the GFP tag (as a positive control of the MCF-7Cx46-GFP results). Our transfection with GFP resulted in cells expressing different degrees of GFP (Supplementary Materials, Figure S1A). Also, Western blot analyses revealed that MCF-7 transfected with Cx46 expressed large amounts of this protein, represented as a prominent band in $46 \mathrm{kDa}$ in each of the three experiments performed. Several bands with lower molecular weights were also observed. As expected, neither MCF-7 or MCF-7 transfected with GFP showed detectable expression of $\mathrm{Cx} 46$. (Supplementary Materials, Figure S1B). In the migration experiments, MCF-7Cx46 show a faster migration velocity than the non-transfected MCF-7 or MCF-7 transfected with GFP alone (Supplementary Materials, Figure S1C,D), strongly supporting our results obtained using MCF-7Cx46-GFP. The analyzes of these results revealed that MCF-7 and MCF-7 GFP after $16 \mathrm{~h}$ closed $~ 20 \%$ of the initial wound area. However, MCF-7 Cx46 closed $\sim 80 \%$ of the initial area in the same period of time (Supplementary Materials, Figure S1D). Similar results were obtained using MCF-7Cx46-GFP cells (see above). These results suggest that Cx46 increases the EMT characteristics of breast cancer cells and therefore could be associated with metastasis in hormone dependent breast cancer. 
A)
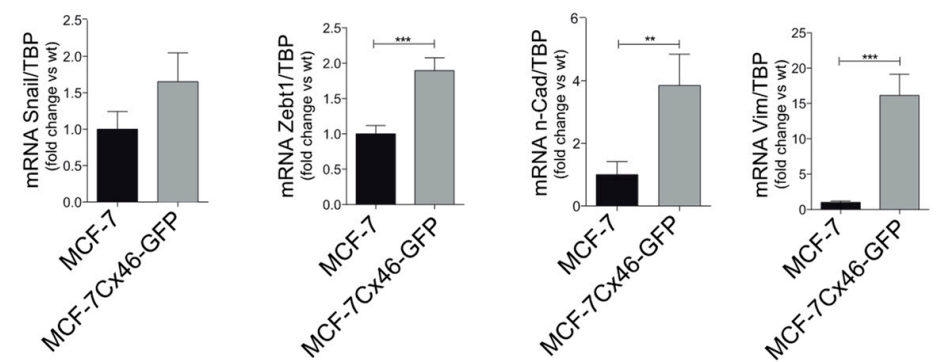

B)

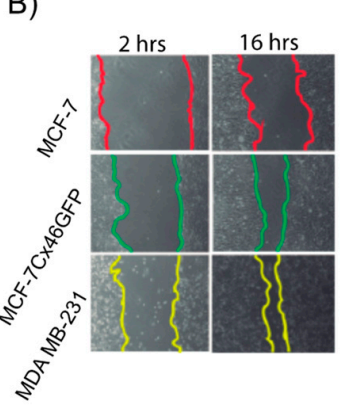

C) $\quad \cdot \mathrm{MCF}-7$

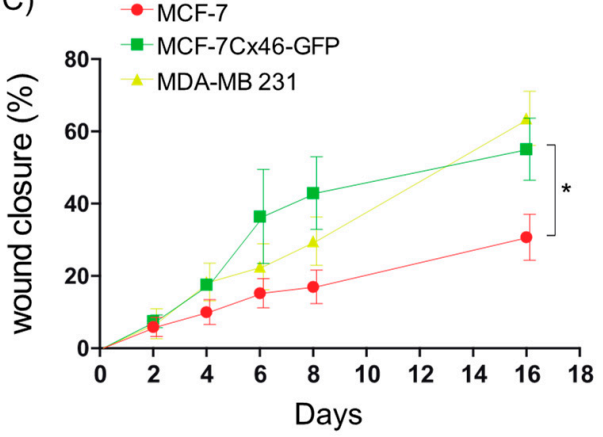

D)

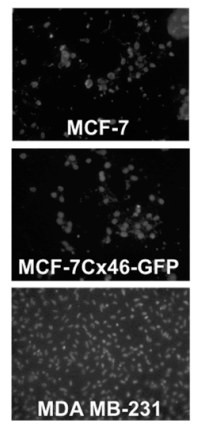

E)

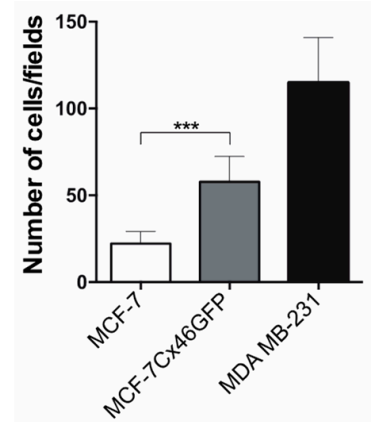

Figure 3. Cx46-GFP increases the expression of EMT-related genes and EMT functional characteristics. (A) The EMT genes Snail, Zebt1, N-Caderin and Vimentin of MCF-7 and MCF-7Cx46-GFP were determined by qRT-PCR. The graph represents the means of three independent experiments. (B) In vitro scratch assays determined differences in breast cancer cell migration. The image in (B) was recorded every $2 \mathrm{~h}$ and photos were obtained at the indicated time points using a $10 \times \mathrm{ob}-$ jective on a Nikon inverted microscope, recorded and measured using the NIS-Element software. The figure shows images at 2 and $16 \mathrm{~h}$ for each cell line, and the color line shows the gap area in the three different cell lines evaluated. (C) Graphical representations of percentage of wound closure area of the three different experiments represented in $\mathrm{B}$. The closing percentage was calculated at different times until the $16 \mathrm{~h}$ period was complete. Data represent the means of three independent experiments $+/-$ SEM. ${ }^{*}$ denotes $p<0.05,{ }^{* *} p<0.01$ and ${ }^{* * *} p<0.001$. (D) Representative images of fields in a Transwell migration assay of MCF-7 (up), MCF-7Cx46-GFP (center), and MDAMB-231 (bottom); cells that crossed the gel matrix were fixed and stained with Dapi. (E) Ten different fields were photographed, and the number of cells was counted and graphed. Data are presented as the means of three independent experiments +/ - SEM.

\subsection{Cx46 Increases the Release of VEGF and Promote Tube Formation in Endothelial Cells}

Angiogenesis is a very important process that enables tumor growth [35], and the production of angiogenic molecules has been associated with CSC niches [35]. Because MCF-7Cx46-GFP presents a higher CSC stemness than its WT counterpart (Figure 2), we explored whether these cells could release angiogenic factors involved in both processes, such as the master regulator of angiogeneisis VEGF. In order to study whether MCF-7Cx46- 
GFPs are producing VEGF, the expression of VEGF in whole cell extracts was determined by Western blot. As expected, an increase of three times the content of VEGF in MCF7Cx46-GFP cells compared to the MCF-7 WT cells (Figure 4A) was observed. To corroborate that these cells are not only producing but also releasing VEGF, we measured their levels in MCF-7Cx46-GFP and MCF-7 WT in the supernatant. We observed that MCF-7Cx46GFP cells released almost twice the VEGF compared to MCF-7 WT cells $(200 \pm 20 \mathrm{v} / \mathrm{s}$ $110 \pm 20 \mathrm{pg} / \mathrm{mL}$ respectively) (Figure 4B). Additionally, we explored whether the VEGF released was able to induce angiogenic-like modifications in HUVEC cells. After $6 \mathrm{~h}$ post exposure to the MCF-7 WT- and MCF-7Cx46-GFP-conditioned media, HUVEC cells present a significant increase in angiogenic modifications, including more and larger junctions (70 $\pm 7 \%$ increase), nodes ( $34 \pm 4 \%$ increase), meshes ( $216 \pm 10 \%$ increase), segments (104 $\pm 4 \%$ increase), and branches (54 $\pm 19 \%$ increase) compared with the conditioned media obtained from MCF-7 WT cells (Figure 4C,D). All these results support a proangiogenic role of $\mathrm{Cx} 46$ when expressed in hormone-dependent breast cancer cells.

A)

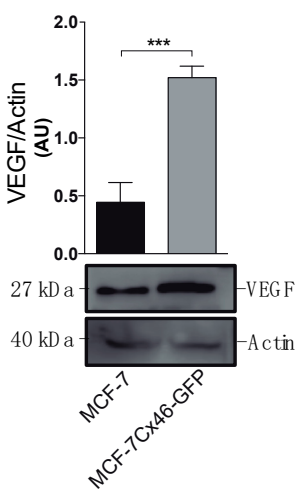

C)

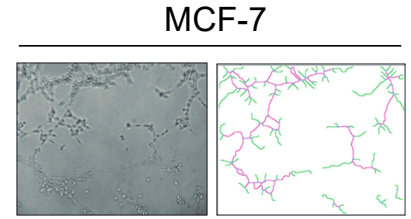

B)

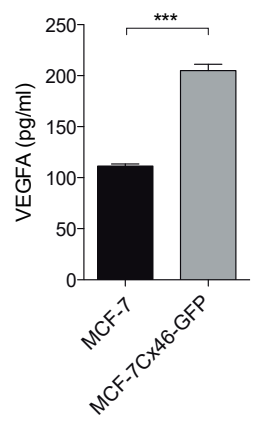

MCF-7Cx46-GFP

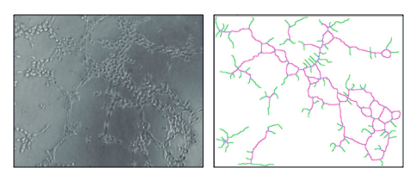

D)

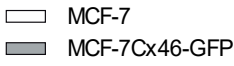

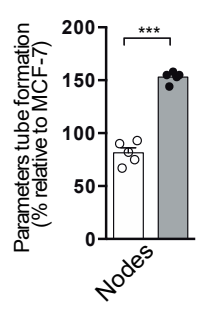

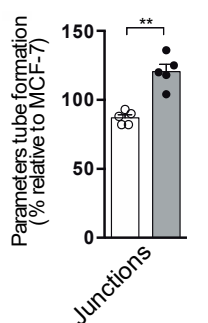

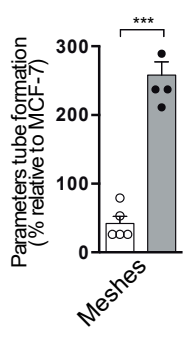

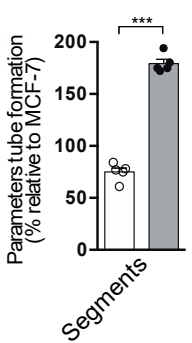

Figure 4. Cx46 increases the expression of angiogenic factors. (A) Representative Western blot of VEGF expression in MCF-7 and MCF-7Cx46-GFP and densitometry quantification of three independent Western blots of VEGF protein expression. (B) Graphical representation of VEGF release in conditioned supernatants media evaluated using a Luminex MAGPIX system. (C) Representative images of tubule structure formation in HUVEC cell incubated with conditioned medium from MCF-7 (left) and MCF-7Cx46-GFP (right) cells. (D) Representative graph quantification of different tube formation parameters (junctions, nodes, meshes, and branches) in HUVEC cells incubated with conditioned medium from MCF-7 and MCF-7Cx46-GFP. After $16 \mathrm{~h}$, the tube formation was examined by phase contrast and the images were captured using an Olympus U-RFL-T camera. Junctions, nodes, meshes, and branches were analyzed using the ImageJ Angiogenesis Analyzer software. Data are presented as the means of three independent experiments $+/-$ SEM. $^{* *} p<0.01$ and ${ }^{* * *} p<0.001$. 


\section{Discussion}

In this work we tested the hypothesis that overexpression of Cx46 can increase the CSC, EMT, and angiogenic characteristics of a human breast cancer cell line known as MCF-7 cells. We observed that the expression of Cx46GFP or Cx46 alone increased CSC and EMT-associated transcription factors, in addition to increasing the expression and release of VEGF angiogenic factor. In agreement with this, MCF-7Cx46-GFP cells presented functional characteristics associated to EMT, CSC, and angiogenic processes. For example, they formed larger tumor spheres and more monoclonal colonies, and they migrated and invaded more than the non-transfected MCF-7 cells. Also, MCF-7Cx46-GFP conditioned media was able to induce angiogenic-like modifications in HUVEC cells, unlike the MCF-7 non-transfected conditioned media.

CSCs are distinguished for being a small population inside of a tumor, but are very relevant for patient survival, since CSCs are directly responsible for tumor growth, chemoresistance, metastasis, and relapse [22-24,36,37]. Accordingly, CSCs have become important targets for new cancer therapies [38-40]. Cx46 is very well correlated with CSC properties in human glioma $[9,10]$. Last year, it was suggested that $C \times 46$ gap junction channels mediate this phenomenon; however, the mechanism behind this cellular transformation was not studied [10]. One possibility is that Cx46 can interact with Sox2, Nanog, or OCT4, increasing their role as transcription factors in proteins needed for CSC phenotype acquisition. Thus, for example, Cx26 in triple negative breast cancer cells promotes CSC self-renewal by forming a complex with Nanog and focal adhesion kinase, resulting in Nanog stabilization [41]. Cx46 has been localized in the nucleus of anterior pituitary folliculostellate cells, where it co-localized with Nopp-140, a nucleolar factor involved in rRNA processing [42]. Thus, nuclear localization of Cx46 and interaction with Sox2, Nanog, or OCT4 can potentially explain our results.

Another important aspect of cancer is the property of some cells to detach from the primary tumor and migrate to the local lymphovascular system, and then to distant organs in a process known as metastasis [30]. To have the ability to migrate, some cells have to lose their polar epithelial phenotype and gain a migratory mesenchymal phenotype in a process known as EMT [30]. Different transcription factors have been suggested to orchestrate the gene expression change associated with EMT, among which, Snail [43-46], Twist [46-49], and ZEB1 $[46,50,51]$ have critical roles. It has been shown that Cx26 upregulates the signaling pathways associated with PI3K/AKT, which in turn increases the EMT characteristics of non-small-cell lung cancer [52]. In the case of Cx46, we recently demonstrated that MCF-7Cx46-GFP cells release extracellular vesicles (EVs, mostly exosomes) containing Cx46 in their membranes [53]. Exosomes contain different cargo molecules, among these, MicroRNAs (miRNAs) [54-57]. The presence of miRNAs has taken on an important role due to their ability to regulate gene expression post-transcriptionally. The presence of the enhanced transfer by Cx46 of information from EVs to recipient cells was associated with an increase of the migratory and invasive capacities of the MCF-7 WT recipient cells [53]. Thus, one possibility to explain our results is a positive loop in which Cx46-positive cells release the EMT-associated miRNAs contained in EVs, which transform or enhance EMT characteristics in Cx46-negative cells.

Angiogenesis is a key process in breast cancer growth, invasion, and metastasis [58]. In breast cancer, mostly the role of $\mathrm{Cx} 43$ has been studied. In this case, downregulation of Cx43 in human breast cancer cell lines (MDA-MB-231 and Hs578T) was correlated with an increase of thrombospondin-1 and VEGF, two antiangiogenic molecules [59]. Moreover, downregulation of $\mathrm{C} \times 43$ in endothelial cells induced by MDA-MB-231 conditioned media induced an increase of endothelial cells proliferation [60]. On the other hand, Cx43 has been identified for its role in reducing the expression of hypoxia induced factor (HIF-1 $\alpha)$ by the downregulation of VEGF in murine cells [61].

In our case, an increase of Cx46 was associated with a higher release of VEGF and an induction of angiogenesis in HUVEC cells. Cx46 was originally detected in lens cells, which is an avascular tissue [62] and implicated in early breast tumor growth [63]. 
Interestingly, renal cancer stem cells release EVs that induce angiogenesis [64,65]. It appears highly likely that the MCF-7Cx46-GFP released EVs [53] which could contain information such as miRNAs that induce VEGF, and other factors associated to angiogenesis, such as HIF- $1 \alpha$.

Thus, this research is the first to demonstrate that $C \times 46$ expression can be associated with a growth of vasculature. We suggest that the same molecular mechanisms that operate in CSC and EMT increase the transcription factors induced by $\mathrm{Cx} 46$, which can also function as a pro-angiogenic factor.

\section{Materials and Methods}

\subsection{Plasmid and Cells}

Stable transfection was performed used a pCMV6-AC-Cx46GFP cloning vector from OriGene Technologies (Origene, Rockville, MD, USA). MCF-7 cells (ATCC) were transfected with Lipofectamine 2000 (Life Technologies, Carlsbad, CA, USA), according to the manufacturer's instructions. Transfected cells were selected with $300 \mu \mathrm{g} / \mathrm{mL}$ of G418 (Gibco). Stable colonies were isolated two weeks later and propagated in DMEM containing G418 at $50 \mu \mathrm{g} / \mathrm{mL}$. The resulting clone was named MCF-7Cx46-GFP. Transient transfection was performed used a human Cx46 in pSFFV-neo mammalian expression plasmid (addgene, Watertown, MA, USA), kindly provided by Dr. Viviana Berthoud (Chicago University, Pediatrics-Hematology and Oncology Departments, Chicago IL). Breast cancer cells lines were purchased from the American Type Culture Collection (ATCC). MCF7, MCF-7Cx46-GFP and MDA-MB-231 were maintained in Dulbecco's modified Eagle's medium (DMEM) (Life Technologies, Carlsbad, CA, USA), supplemented with 10\% heat inactivated fetal bovine serum (FBS) (Life Technologies, Carlsbad, CA, USA) and penicillin/Streptomycin (100 U/mL, $100 \mu$ leme Streptomycin). Cells were maintained at $37^{\circ} \mathrm{C}$ in a $5 \% \mathrm{CO}_{2}$ humidified incubator.

\subsection{Western Blot}

Briefly, cells were lysed in RIPA buffer supplemented with protease inhibitors (Roche). The protein concentration was determined using a protein assay kit (ThermoFisher Scientific, Waltham, MA, USA) and read in a Qubit 3.0 Fluorometer (ThermoFisher Scientific, Waltham, MA, USA). Of the total protein from the cell lysates, $100 \mu \mathrm{g}$ was resolved with 10\% SDS PAGE gel by PAGE and transferred to a nitrocellulose membrane (Bio-Rad, Hercules, CA, USA). Membranes were incubated with the following primary antibodies: anti Cx46 (Santa Cruz Biotechnology; 1:500), anti Cx43 (Santa Cruz Biotechnology; 1:500), and beta actin (Santa Cruz Biotechnology, 1:5000). All secondary antibodies were horseradish protein (HRP) conjugates (Abcam). Protein bands were detected using Immobilon Forte Western HRP substrate (Millipore, Burlington, MA, USA) and visualized with LI-COR C-Digit Chemiluminescense Western Blot Scanner systems (LI-COR, Inc, Lincoln, NE, USA).

\subsection{Clonogenic Assay}

The MCF-7 and MCF-7Cx46-GFP breast cancer cell lines were seeded in $35 \mathrm{~mm}$ culture plates, 200 cells were seeded in triplicate. The cells were kept at $37{ }^{\circ} \mathrm{C}$ in $5 \% \mathrm{CO}_{2}$ for 14 days, and the culture media were changed every 2 days. After 14 days, the cells were washed with 1 X PBS, fixed with $70 \%$ ethanol, and stained with $0.5 \%$ crystal violet. The colonies contained in each plate were photographed using a magnifying glass, to later be incubated with lysis buffer ( $150 \mathrm{mM} \mathrm{NaCl}, 1 \% \mathrm{NP} 40,50 \mathrm{mM}$ Tris $\mathrm{pH}$ 8.0). The samples were diluted in 1X PBS to be measured in a spectrophotometer at $595 \mathrm{~nm}$. The measurement results were reported as arbitrary units of absorbance (AU).

\subsection{Sphere Assay}

The monolayers of MCF-7 and MCF-7Cx46-GFP were harvested and dissociated into single cells by trypsinization. Spheroid formation was performed by seeding the cells 
at a density of $5 \times 10^{4}$ cells in an ultra-low attachment six-well plate (Corning). Cells were cultured in $2 \mathrm{~mL} /$ well of low serum DMEM medium, supplemented with $0.025 \%$ of human epidermal growth factor (hEGF), $0.05 \%$ insulin, $0.0034 \%$ hydrocortisone, and $0.05 \%$ heparin. Spheroid formation was monitored each day, and $500 \mathrm{ul}$ of fresh medium was added. The size of each sphere was determined by microscope visualization in a Nikon Eclipse Ti-U inverted microscope (Centro de Fisiología Celular e integrativa, Universidad del Desarrollo, Santiago, Chile). The area of the spheres was measured using NIS-Element AR 4.3 Software (Nikon, Melville, NY, USA).

\subsection{Migration Assay}

Briefly, $6.0 \times 10^{5}$ cells were plated in 35-mm culture dishes. After $24 \mathrm{~h}$, the cell monolayers were wounded with a $200-\mu \mathrm{L}$ sterile pipette tip, the cellular debris was washed with PBS, and the medium was replaced with Dulbecco's modified Eagle's medium (Life Technologies, Waltham, MA, USA), supplemented with 10\% FBS. The wound was photographed at different times $(0,2,4,8$, and $16 \mathrm{~h})$ with a Nikon Eclipse Ti-U inverted microscope (Centro de Fisiología Celular e integrativa, Universidad del Desarrollo, Santiago, Chile). The area of wound closure was measured using the NIS-Element AR 4.3 Software (Nikon, Melville, NY, USA).

\subsection{Transwell Invasion Assay}

Transwell chambers with 24 wells and an $8 \mu \mathrm{m}$ polycarbonate membrane (Corning, NY, USA) were used, following the manufacturer's protocol. The upper chambers were coated with $100 \mu \mathrm{L}$ of DMEM-diluted Geltrex matrix (Gibco) and incubated at $37^{\circ} \mathrm{C}$ for $6 \mathrm{~h}$ to allow the gel to solidify. The cultured cells were detached using $0.25 \%$ trypsin-EDTA solution and counted in a Neubauer chamber. Then, $1 \times 10^{5}$ cells were seeded into the upper chambers in $200 \mu \mathrm{L}$ of serum-free media. A total of $500 \mu \mathrm{L}$ of complete medium was added to the lower chamber as a chemo attractant. After $12 \mathrm{~h}$, the cells remaining in the upper side of the polycarbonate membrane were removed with cotton swabs. Bottom chambers containing invasive cells were washed (twice with PBS), fixed in $100 \%$ methanol, and stained with DAPI ( $5 \mu \mathrm{m})$ for $5 \mathrm{~min}$. Ten visual fields of each insert were randomly chosen, and photographed at $4 \mathrm{x}$ magnification. The number of cells/fields was quantified using ImageJ software (NIH, Bethesda, MD, USA).

\subsection{Angiogenesis Assay}

Tube formation in Matrigel (Corning) was used as a functional assay to evaluate the angiogenic properties of MenSCs. Briefly, human umbilical vein endothelial cells (HUVECs) were seeded in 96-well plates precoated with $50 \mu \mathrm{L}$ of growth factor reduced Matrigel (Corning, Manassas, VA, USA) at a density of $2 \times 10^{4}$ cells/well in the conditioned medium (CM) harvested previously. After $6 \mathrm{~h}$, tube formation was examined by phase contrast, and the images were captured using a Nikon Eclipse Ti-U at $10 \times$ magnification. The nodes, junctions, meshes, segments, and branches of the tubes were analyzed using the ImageJ Angiogenesis Analyzer software, version 2.02 (National Institute of Health, Bethesda, MD, USA).

\subsection{Luminex Assay}

SecVEGF was measured using a commercial multiplex fluorescent bead-based immunoassay (R\&D Systems, Minneapolis, MN, USA) following the manufacturer's instructions. The vascular endothelial growth factor A (VEGFA) of the concentrations were determined in CM of MCF-7 and MCF-7Cx46-GFP using a MAGPIX system (ThermoFisher Scientific, Waltham, MA, USA).

\subsection{Reverse Transcription-Quantitative Polymerase Chain Reaction}

Total RNA from the MCF-7 and MCF-7Cx46-GFP was isolated with the Trizol reagent (Life Technologies, Carlsbad, CA, USA). Total RNA concentration was quantified using a 
Nanodrop (ThermoFisher Scientific, Waltham, MA, USA), following the manufacturer's instructions. The complementary DNA (cDNA) was generated using SuperScript ${ }^{\mathrm{TM}}$ II Reverse Transcriptase (Invitrogen, Carlsbad, CA, USA). The reverse transcription (RT) was performed in $12 \mu \mathrm{L}$ of reaction: $1 \mu \mathrm{L}$ of deoxynucleotides (dNTP) $(10 \mathrm{mM}), 1 \mu \mathrm{L}$ of random primers $(100 \mathrm{ng} / \mu \mathrm{L}), 1 \mu \mathrm{g}$ of total RNA treated with DNAse, and nuclease-free water. The mix was incubated at $65^{\circ} \mathrm{C}$ for $5 \mathrm{~min}$. After the incubation, $4 \mu \mathrm{L}$ of $5 \mathrm{X}$ firststrand buffer, $2 \mu \mathrm{L}$ of Dithiothreitol (DTT) $(0.1 \mathrm{M})$, and $1 \mu \mathrm{L}$ of RNAseOUT (30 U/ $\mu \mathrm{L}$ ) were added to the mix. The mix was incubated at $25{ }^{\circ} \mathrm{C}$ for $2 \mathrm{~min}$, and $1 \mu \mathrm{L}$ of SuperScript ${ }^{\mathrm{TM}}$ II Reverse Transcriptase (200 U) was added. The complete reaction was incubated at $25{ }^{\circ} \mathrm{C}$ for $10 \mathrm{~min}, 42{ }^{\circ} \mathrm{C}$ for $50 \mathrm{~min}$, and inactivated at $70{ }^{\circ} \mathrm{C}$ for $15 \mathrm{~min}$. Quantitative real-time PCR (qPCR) was performed using the Brilliant II QPCR Master Mix (Agilent Technologies, Santa Clara, CA, USA) mixing $2.5 \mu \mathrm{L}$ of diluted cDNA, 200 nmoles of each primer, $5 \mu \mathrm{L}$ of Brilliant II QPCR Master Mix, and nuclease-free water in a final volume of $10 \mu \mathrm{L}$. The reaction was incubated $10 \mathrm{~min}$ at $95^{\circ} \mathrm{C}, 40$ cycles of $20 \mathrm{~s}$ at $95^{\circ} \mathrm{C}, 20 \mathrm{~s}$ at $60-62{ }^{\circ} \mathrm{C}, 20 \mathrm{~s}$ at $72{ }^{\circ} \mathrm{C}$, and finally $10 \mathrm{~s}$ at $95{ }^{\circ} \mathrm{C}, 5 \mathrm{~s}$ to $25^{\circ} \mathrm{C}, 1 \mathrm{~s}$ at $55^{\circ} \mathrm{C}$, and $1 \mathrm{~s}$ at $95^{\circ} \mathrm{C}$ in the Stratagene Mx3000P system (Agilent Technologies, Santa Clara, CA, USA). The primers used to analyze the expression of the epithelial-to-mesenchymal transition genes were: N-Cad: forward 5'-CGGGAGAAATTGCAGGAGGA-3' ${ }^{\prime}$, reverse $5^{\prime}$ GGCAAGTTGATTGGAGGG ATG-3', Vimentin: forward 5'-CGGGAGAAATTGCAGGAG GA-3' ${ }^{\prime}$, reverse 5' ${ }^{\prime}$-AAGGTCAAGACGTGCCAGAG-3' ${ }^{\prime}$ SNAIL: forward 5'-CTTCCA GCA GCCCTACGAC-3', reverse 5'-GACAGAGTCCCAGATGAGCA-3' ${ }^{\prime}$, and Zeb1: forward 5'-AAGTGGCGGTAGATGGTAATG-3', reverse 5'-AGGAAGACTGATGGCTGAAATA A-3' ${ }^{\prime}$, and the primers used to analyzed the expression of the stemness genes were: Oct4: forward 5'-AGGTATTCAGCCAAACGACCA-3', reverse 5'- TCGATACTGGTTCGCT TTCTC-3', Nanog: forward 5'-CATGAGTGTGGATCCAGCTTG-3', reverse 5'-CCTGAA TAAGCAGATCCATGG-3' ${ }^{\prime}$, and Sox2: forward 5'-AGCTACAGCATGATGCAGGA-3' ${ }^{\prime}$, reverse $5^{\prime}$-GAGTAGGACATGCTGTAGGT-3', Glyceraldehyde 3-phosphate dehydrogenase (GAPDH) was used as a housekeeping gene: forward 5'-GGAAGATGGTGAT GGGATTTC- $3^{\prime}$, reverse $5^{\prime}$-GAAGGTGAAGGTCGGAGTCAA- $3^{\prime}$. All the primers were synthesized by IDT DNA technologies (Coralville, IA, USA). Transcript levels were quantified using the comparative CT method.

\subsection{Statistical Analysis}

All results are expressed as the mean \pm standard error of the mean (SEM). Data were processed using GraphPad software, Inc. (http:/ / www.graphpad.com, accessed on 5 November 2021) and analyzed for statistical significance using the student's $t$-test; a $p$-value $<0.05$ was considered significant.

\section{Conclusions}

We show here that Cx46 expression enhances the CSC, EMT, and angiogenic characteristics on MCF-7 breast cancer cells. It increases the transcription factors associated with CSC and EMT. Additionally, Cx46-expressing cells release more VEGF to the extracellular milieu, where it induces angiogenesis in Huvec cells. Our data indicate an important role of $\mathrm{Cx} 46$ as a driver of cancer aggressiveness.

Supplementary Materials: The following are available online at https:/ /www.mdpi.com/article/10 .3390/ijms222212604/s1.

Author Contributions: R.A.A. and M.V.-G. conceived and designed research, R.A.A. performed all experiments and analyzed the data; D.H.-S. performed angiogenesis image analysis; R.A.A. prepared the figures; R.A.A., M.A.R. and M.V.-G. resources; R.A.A. and M.A.R., writing original draft, R.A.A., M.V.-G. and M.A.R. review and editing. All authors have read and agreed to the published version of the manuscript.

Funding: This research was funded by FONDECYT Iniciación 11200835 and proyecto interno UDD to R.A.A, FONDECYT regular 1160227 to M.A.R and FONDECYT Regular 1190928 to M.V.-G. 
Institutional Review Board Statement: Not applicable.

Informed Consent Statement: Not applicable.

Data Availability Statement: Data will be available if requested.

Conflicts of Interest: The authors declare no conflict of interest, financial or otherwise.

\section{References}

1. Sáez, J.C.; Berthoud, V.M.; Brañes, M.C.; Martínez, A.D.; Beyer, E.C. Plasma Membrane Channels Formed by Connexins: Their Regulation and Functions. Physiol. Rev. 2003, 83, 1359-1400. [CrossRef] [PubMed]

2. Retamal, M.A.; Reyes, E.P.; García, I.E.; Pinto, B.; Martínez, A.D.; González, C. Diseases associated with leaky hemichannels. Front. Cell. Neurosci. 2015, 9, 267. [CrossRef] [PubMed]

3. Yamasaki, H. Role of cell-cell communication in tumor suppression. Immunol. Ser. 1990, 51, 245-266. [PubMed]

4. Aasen, T.; Leithe, E.; Graham, S.V.; Kameritsch, P.; Mayán, M.D.; Mesnil, M.; Pogoda, K.; Tabernero, A. Connexins in cancer: Bridging the gap to the clinic. Oncogene 2019, 38, 4429-4451. [CrossRef]

5. Paul, D.L.; Ebihara, L.; Takemoto, L.J.; Swenson, K.I.; Goodenough, D.A. Connexin46, a novel lens gap junction protein, induces voltage-gated currents in nonjunctional plasma membrane of Xenopus oocytes. J. Cell Biol. 1991, 115, 1077-1089. [CrossRef]

6. Avanzo, J.L.; Mesnil, M.; Hernandez-Blazquez, F.J.; da Silva, T.C.; Fukumasu, H.; Mori, C.M.C.; Yamasaki, H.; Dagli, M.L.Z. Altered expression of connexins in urethane-induced mouse lung adenomas. Life Sci. 2006, 79, 2202-2208. [CrossRef]

7. Sanches, D.S.; Pires, C.G.; Fukumasu, H.; Cogliati, B.; Matsuzaki, P.; Chaible, L.M.; Torres, L.N.; Ferrigno, C.R.A.; Dagli, M.L.Z. Expression of Connexins in Normal and Neoplastic Canine Bone Tissue. Vet. Pathol. 2009, 46, 846-859. [CrossRef]

8. Banerjee, D.; Gakhar, G.; Madgwick, D.; Hurt, A.; Takemoto, D.; Nguyen, T.A. A novel role of gap junction connexin46 protein to protect breast tumors from hypoxia. Int. J. Cancer 2010, 127, 839-848. [CrossRef]

9. Hitomi, M.; Deleyrolle, L.P.; Mulkearns-Hubert, E.E.; Jarrar, A.; Li, M.; Sinyuk, M.; Otvos, B.; Brunet, S.; Flavahan, W.A.; Hubert, C.G.; et al. Differential Connexin Function Enhances Self-Renewal in Glioblastoma. Cell Rep. 2015, 11, 1031-1042. [CrossRef]

10. Mulkearns-Hubert, E.E.; Torre-Healy, L.A.; Silver, D.J.; Eurich, J.T.; Bayik, D.; Serbinowski, E.; Hitomi, M.; Zhou, J.; Zhang, R.; Sprowls, S.A.; et al. Development of a Cx46 Targeting Strategy for Cancer Stem Cells. Cell Rep. 2019, 27, 1062-1072. [CrossRef]

11. Burr, D.B.; Molina, S.A.; Banerjee, D.; Low, D.M.; Takemoto, D.J. Treatment with connexin 46 siRNA suppresses the growth of human Y79 retinoblastoma cell xenografts in vivo. Exp. Eye Res. 2011, 92, 251-259. [CrossRef]

12. Rich, J.N. Cancer stem cells: Understanding tumor hierarchy and heterogeneity. Medicine 2016, 95, S2-S7. [CrossRef]

13. O'Brien, C.A.; Kreso, A.; Jamieson, C.H.M. Cancer stem cells and self-renewal. Clin. Cancer Res. 2010, 16, 3113-3120. [CrossRef]

14. Abbaszadegan, M.R.; Bagheri, V.; Razavi, M.S.; Momtazi, A.A.; Sahebkar, A.; Gholamin, M. Isolation, identification, and characterization of cancer stem cells: A review. J. Cell. Physiol. 2017, 232, 2008-2018. [CrossRef]

15. Celià-Terrassa, T.; Jolly, M.K. Cancer Stem Cells and Epithelial-to-Mesenchymal Transition in Cancer Metastasis. Cold Spring Harb. Perspect. Med. 2020, 10, a036905. [CrossRef]

16. Mao, X.-Y.; Li, Q.-Q.; Gao, Y.-F.; Zhou, H.-H.; Liu, Z.-Q.; Jin, W.-L. Gap junction as an intercellular glue: Emerging roles in cancer EMT and metastasis. Cancer Lett. 2016, 381, 133-137. [CrossRef]

17. Levenson, A.S.; Jordan, V.C. MCF-7: The first hormone-responsive breast cancer cell line. Cancer Res. 1997, 57, 3071-3078.

18. Wang, Z.; Schey, K.L. Phosphorylation and truncation sites of bovine lens connexin 46 and connexin 50. Exp. Eye Res. 2009, 89, 898-904. [CrossRef]

19. Slavi, N.; Wang, Z.; Harvey, L.; Schey, K.L.; Srinivas, M. Identification and Functional Assessment of Age-Dependent Truncations to Cx46 and Cx50 in the Human Lens. Investig. Opthalmology Vis. Sci. 2016, 57, 5714. [CrossRef]

20. Gordon, L.A.; Mulligan, K.T.; Maxwell-Jones, H.; Adams, M.; Walker, R.A.; Jones, J.L. Breast cell invasive potential relates to the myoepithelial phenotype. Int. J. Cancer 2003, 106, 8-16. [CrossRef]

21. Holliday, D.L.; Speirs, V. Choosing the right cell line for breast cancer research. Breast Cancer Res. 2011, 13, 215. [CrossRef]

22. Najafi, M.; Farhood, B.; Mortezaee, K. Cancer stem cells (CSCs) in cancer progression and therapy. J. Cell. Physiol. 2018, 234, 8381-8395. [CrossRef]

23. Li, N.; Zhu, Y. Targeting liver cancer stem cells for the treatment of hepatocellular carcinoma. Therap. Adv. Gastroenterol. 2019, 12, 175628481882156. [CrossRef]

24. Lytle, N.K.; Barber, A.G.; Reya, T. Stem cell fate in cancer growth, progression and therapy resistance. Nat. Rev. Cancer 2018, 18, 669-680. [CrossRef]

25. Mohan, A.; Rajan, R.R.; Mohan, G.; Puthenveettil, P.K.; Maliekal, T.T. Markers and Reporters to Reveal the Hierarchy in Heterogeneous Cancer Stem Cells. Front. Cell Dev. Biol. 2021, 9, 1325. [CrossRef]

26. Kim, R.-J.; Nam, J.-S. OCT4 Expression Enhances Features of Cancer Stem Cells in a Mouse Model of Breast Cancer. Lab. Anim. Res. 2011, 27, 147. [CrossRef]

27. Leis, O.; Eguiara, A.; Lopez-Arribillaga, E.; Alberdi, M.J.; Hernandez-Garcia, S.; Elorriaga, K.; Pandiella, A.; Rezola, R.; Martin, A.G. Sox2 expression in breast tumours and activation in breast cancer stem cells. Oncogene 2012, 31, 1354-1365. [CrossRef]

28. Lee, C.H.; Yu, C.C.; Wang, B.Y.; Chang, W.W. Tumorsphere as an effective in vitro platform for screening anticancer stem cell drugs. Oncotarget 2016, 7, 1215-1226. [CrossRef] 
29. Gou, S.; Liu, T.; Wang, C.; Yin, T.; Li, K.; Yang, M.; Zhou, J. Establishment of clonal colony-forming assay for propagation of pancreatic cancer cells with stem cell properties. Pancreas 2007, 34, 429-435. [CrossRef] [PubMed]

30. Celià-Terrassa, T.; Kang, Y. Distinctive properties of metastasis-initiating cells. Genes Dev. 2016, 30, 892-908. [CrossRef] [PubMed]

31. Wang, J.; Zhang, Z.; Li, R.; Mao, F.; Sun, W.; Chen, J.; Zhang, H.; Bartsch, J.W.; Shu, K.; Lei, T. ADAM12 induces EMT and promotes cell migration, invasion and proliferation in pituitary adenomas via EGFR/ERK signaling pathway. Biomed. Pharmacother. 2018, 97, 1066-1077. [CrossRef] [PubMed]

32. Son, H.; Moon, A. Epithelial-mesenchymal transition and cell invasion. Toxicol. Res. 2013, 26, 245-252. [CrossRef] [PubMed]

33. Liang, C.C.; Park, A.Y.; Guan, J.L. In vitro scratch assay: A convenient and inexpensive method for analysis of cell migration in vitro. Nat. Protoc. 2007, 2, 329-333. [CrossRef] [PubMed]

34. Albini, A. Extracellular matrix invasion in metastases and angiogenesis: Commentary on the Matrigel "chemoinvasion assay". Cancer Res. 2016, 76, 4595-4597. [CrossRef]

35. Zhao, Y.; Bao, Q.; Renner, A.; Camaj, P.; Eichhorn, M.; Ischenko, I.; Angele, M.; Kleespies, A.; Jauch, K.W.; Bruns, C. Cancer stem cells and angiogenesis. Int. J. Dev. Biol. 2011, 55, 477-482. [CrossRef]

36. Ayob, A.Z.; Ramasamy, T.S. Cancer stem cells as key drivers of tumour progression. J. Biomed. Sci. 2018, 25, 20. [CrossRef]

37. Nandy, S.B.; Lakshmanaswamy, R. Cancer Stem Cells and Metastasis. Prog. Mol. Biol. Transl. Sci. 2017, 151, 137-176. [CrossRef]

38. Pan, Y.; Ma, S.; Cao, K.; Zhou, S.; Zhao, A.; Li, M.; Qian, F.; Zhu, C. Therapeutic approaches targeting cancer stem cells. J. Cancer Res. Ther. 2018, 14, 1469-1475. [CrossRef]

39. Visioli, A.; Giani, F.; Trivieri, N.; Pracella, R.; Miccinilli, E.; Cariglia, M.G.; Palumbo, O.; Arleo, A.; Dezi, F.; Copetti, M.; et al. Stemness underpinning all steps of human colorectal cancer defines the core of effective therapeutic strategies. EBioMedicine 2019, 44, 346-360. [CrossRef]

40. Vander Linden, C.; Corbet, C. Therapeutic Targeting of Cancer Stem Cells: Integrating and Exploiting the Acidic Niche. Front. Oncol. 2019, 9, 159. [CrossRef]

41. Thiagarajan, P.S.; Sinyuk, M.; Turaga, S.M.; Mulkearns-hubert, E.E.; Hale, J.S.; Rao, V.; Demelash, A.; Saygin, C.; Alban, T.J.; Hitomi, M.; et al. Cx26 drives self-renewal in triple-negative breast cancer via interaction with NANOG and focal adhesion kinase. Nat. Commun. 2018, 9, 578. [CrossRef]

42. Vitale, M.L.; Garcia, C.J.; Akpovi, C.D.; Pelletier, R.-M. Distinctive actions of connexin 46 and connexin 50 in anterior pituitary folliculostellate cells. PLoS ONE 2017, 12, e0182495. [CrossRef]

43. Wang, Y.; Shi, J.; Chai, K.; Ying, X.; Zhou, B. The Role of Snail in EMT and Tumorigenesis. Curr. Cancer Drug Targets 2014, 13, 963-972. [CrossRef]

44. Smith, B.N.; Burton, L.J.; Henderson, V.; Randle, D.D.; Morton, D.J.; Smith, B.A.; Taliaferro-Smith, L.; Nagappan, P.; Yates, C.; Zayzafoon, M.; et al. Snail promotes epithelial mesenchymal transition in breast cancer cells in part via activation of nuclear ERK2. PLoS ONE 2014, 9, e104987. [CrossRef]

45. Yang, X.; Han, M.; Han, H.; Wang, B.; Li, S.; Zhang, Z.; Zhao, W. Silencing Snail suppresses tumor cell proliferation and invasion by reversing epithelial-to-mesenchymal transition and arresting G2/M phase in non-small cell lung cancer. Int. J. Oncol. 2017, 50, 1251-1260. [CrossRef]

46. Baulida, J. Epithelial-to-mesenchymal transition transcription factors in cancer-associated fibroblasts. Mol. Oncol. 2017, 11, 847-859. [CrossRef]

47. Wang, Y.; Liu, J.; Ying, X.; Lin, P.C.; Zhou, B.P. Twist-mediated Epithelial-mesenchymal Transition Promotes Breast Tumor Cell Invasion via Inhibition of Hippo Pathway. Sci. Rep. 2016, 6, 24606. [CrossRef]

48. Kang, Y.; Massagué, J. Epithelial-mesenchymal transitions: Twist in development and metastasis. Cell 2004, 118, 277-279. [CrossRef]

49. Zhang, Y.-Q.; Wei, X.-L.; Liang, Y.-K.; Chen, W.-L.; Zhang, F.; Bai, J.-W.; Qiu, S.-Q.; Du, C.-W.; Huang, W.-H.; Zhang, G.-J. Over-Expressed Twist Associates with Markers of Epithelial Mesenchymal Transition and Predicts Poor Prognosis in Breast Cancers via ERK and Akt Activation. PLoS ONE 2015, 10, e0135851. [CrossRef]

50. Zhang, P.; Sun, Y.; Ma, L. ZEB1: At the crossroads of epithelial-mesenchymal transition, metastasis and therapy resistance. Cell Cycle 2015, 14, 481-487. [CrossRef]

51. Zhang, Y.; Xu, L.; Li, A.; Han, X. The roles of ZEB1 in tumorigenic progression and epigenetic modifications. Biomed. Pharmacother. 2019, 110, 400-408. [CrossRef]

52. Yang, J.; Qin, G.; Luo, M.; Chen, J.; Zhang, Q.; Li, L.; Pan, L.; Qin, S. Reciprocal positive regulation between Cx26 and PI3K/Akt pathway confers acquired gefitinib resistance in NSCLC cells via GJIC-independent induction of EMT. Cell Death Dis. 2015, 6, e1829. [CrossRef]

53. Acuña, R.A.; Varas-Godoy, M.; Berthoud, V.M.; Alfaro, I.E.; Retamal, M.A. Connexin-46 contained in extracellular vesicles enhance malignancy features in breast cancer cells. Biomolecules 2020, 10, 676. [CrossRef]

54. Zhang, M.; Jabbari, N.; Satpathy, M.; Matyunina, L.V.; Wang, Y.; McDonald, L.D.E.; McDonald, J.F. Sequence diverse miRNAs converge to induce mesenchymal-to-epithelial transition in ovarian cancer cells through direct and indirect regulatory controls. Cancer Lett. 2019, 459, 168-175. [CrossRef]

55. Temoche-Diaz, M.M.; Shurtleff, M.J.; Nottingham, R.M.; Yao, J.; Fadadu, R.P.; Lambowitz, A.M.; Schekman, R. Distinct mechanisms of microrna sorting into cancer cell-derived extracellular vesicle subtypes. Elife 2019, 8, e47544. [CrossRef]

56. Di Leva, G.; Garofalo, M.; Croce, C.M. microRNAs in cancer. Annu. Rev. Pathol. 2014, 9, 287-314. [CrossRef] 
57. Hamam, R.; Hamam, D.; Alsaleh, K.A.; Kassem, M.; Zaher, W.; Alfayez, M.; Aldahmash, A.; Alajez, N.M. Circulating microRNAs in breast cancer: Novel diagnostic and prognostic biomarkers. Cell Death Dis. 2017, 8, e3045. [CrossRef]

58. Varinska, L.; Gal, P.; Mojzisova, G.; Mirossay, L.; Mojzis, J. Soy and breast cancer: Focus on angiogenesis. Int. J. Mol. Sci. 2015, 16, 11728. [CrossRef]

59. Shao, Q.; Wang, H.; McLachlan, E.; Veitch, G.I.L.; Laird, D.W. Down-regulation of Cx43 by retroviral delivery of small interfering RNA promotes an aggressive breast cancer cell phenotype. Cancer Res. 2005, 65, 2705-2711. [CrossRef]

60. Choudhary, M.; Naczki, C.; Chen, W.; Barlow, K.D.; Case, L.D.; Metheny-Barlow, L.J. Tumor-induced loss of mural Connexin 43 gap junction activity promotes endothelial proliferation. BMC Cancer 2015, 15, 427. [CrossRef]

61. Wang, W.K.; Chen, M.C.; Leong, H.F.; Kuo, C.Y.; Kuo, C.Y.; Lee, C.H. Connexin 43 suppresses tumor angiogenesis by downregulation of vascular endothelial growth factor via hypoxic-induced factor- $1 \alpha$. Int. J. Mol. Sci. 2014, 16, 439-451. [CrossRef] [PubMed]

62. Beyer, E.C.; Berthoud, V.M. Connexin hemichannels in the lens. Front. Physiol. 2014, 5, 20. [CrossRef] [PubMed]

63. Banerjee, D. Connexin's connection in breast cancer growth and progression. Int. J. Cell Biol. 2016, 2016, 1-11. [CrossRef] [PubMed]

64. Grange, C.; Tapparo, M.; Collino, F.; Vitillo, L.; Damasco, C.; Deregibus, M.C.; Tetta, C.; Bussolati, B.; Camussi, G. Microvesicles released from human renal cancer stem cells stimulate angiogenesis and formation of lung premetastatic niche. Cancer Res. 2011, 71, 5346-5356. [CrossRef] [PubMed]

65. Aslan, C.; Maralbashi, S.; Salari, F.; Kahroba, H.; Sigaroodi, F.; Kazemi, T.; Kharaziha, P. Tumor-derived exosomes: Implication in angiogenesis and antiangiogenesis cancer therapy. J. Cell. Physiol. 2019, 234, 16885-16903. [CrossRef] 